\title{
Effect of Platelet Releasate on Bone Cell Migration and Recruitment In Vitro
}

\author{
Wanda E. Oprea, BASc* \\ Jeffrey M. Karp, BEng ${ }^{\star \dagger}$ \\ Morris M. Hosseini, PhD* \\ John E. Davies, BDS, DSc*†‡
}

Toronto, Ontario, Canada

The use of platelets and platelet products has become increasingly popular clinically as a means of accelerating endosseous wound healing. It is likely that growth factors released by activated platelets at the site of injury play a role in bone regeneration by stimulating the migration and proliferation of bone cells. In this study, a novel in vitro assay was developed to study the effects of platelet releasate (PR) collected from activated platelet concentrate on rat bone marrow-derived cells. Cultures of primary rat bone marrow cells were overlaid with a fibrin matrix, and the number of cells migrating within the three-dimensional matrix and the leading front of migration were quantified. The addition of PR to the top of the fibrin gels at different time points caused a $25 \%$ increase in the leading front of migration and a 3.5-fold increase in the number of migrating cells. Platelet releasate was also shown to have a mitogenic effect on bone cells in proliferation studies. Comparison between migration and proliferation data indicated that PR stimulates the initial recruitment of bone marrow cells to migration. This assay further allowed the determination that rat bone marrow cells are capable of exerting contractile forces on fibrin matrices and that matrix contraction is directly related to the migratory activity of cells. The results provide a potential mechanism to explain why biologically active platelet-derived factors enhance endosseous wound healing.

From the *Institute of Biomaterials and Biomedical Engineering, ${ }^{+}$Department of Chemical Engineering and Applied Chemistry, and ₹Faculty of Dentistry, University of Toronto, Toronto, Ontario Canada.

Address correspondence to Dr Davies, Institute of Biomaterials and Biomedical Engineering, University of Toronto, 4 Taddle Creek Road, Toronto, Ontario, Canada M5S 3G9; e-mail: davies@ecf.utoronto.ca
Key Words: Bone cells, platelets, fibrin, wound healing, migration, proliferation

 ndosseous wound healing involves a complex cascade of biological events that ultimately result in the regeneration of bone. As an immediate result of injury, local extravasated blood fills the healing compartment and leads to the formation of a blood clot. The provisional network of fibrin fibers, which forms the structural component of the clot, serves as a matrix for the inward migration of osteogenic cells that originate in the marrow and on endosteal surfaces. ${ }^{1}$ The subsequent differentiation of these migratory cells to secretory osteoblasts results in de novo bone formation. In addition to the matrix component, a blood clot contains a rich mixture of growth factors released by activated blood cells. Most notable of these are platelets; on activation, they release a library of growth factors such as platelet-derived growth factor (PDGF) and transforming growth factor- $\beta$ (TGF- $\beta$ ). Conventional wisdom holds that these factors play an important role in the regulation of the wound healing cascade ${ }^{2,3}$ based on in vitro and in vivo evidence of their stimulatory effects on the proliferation and migration of various cell types. ${ }^{4-6}$

Such thinking has encouraged the development of new healing therapies that incorporate platelets and their products to enhance and accelerate the wound healing process. These approaches have been applied in a variety of clinical areas, including plastic surgery and orthopedic surgery, with general success. For example, in dermal wound healing studies, an acceleration of granulation tissue formation and healing was observed when PDGF, platelet concentrate, or platelet releasate (PR) was applied at injury sites. ${ }^{5,7}$ At endosseous sites, the application of PDGF has been shown to promote bone formation, ${ }^{8}$ whereas platelet concentrate has been used successfully to enhance lumbar spinal fusion. ${ }^{9}$ Platelet con- 
centrate has also been shown to double the rate of bone formation and improve bone density after bone grafting, ${ }^{10}$ which has stimulated the development of several commercially available platelet concentrating machines. ${ }^{11}$ Despite such reports, however, clinical success has been inconsistent, and more basic research is required to elucidate thoroughly the underlying mechanisms of platelet growth factor enhancement of endosseous wound healing.

The specific mechanisms of action of platelets during wound healing have been deduced in large part from in vitro studies. Such work has concentrated on the effects of individual platelet growth factors such as PDGF on fibroblasts and inflammatory cells. In the dermal wound literature, PDGF and TGF $\beta$ have been shown to be mitogenic for fibroblasts. ${ }^{12-14}$ Migration assays designed to investigate the directed migration of cells in response to a soluble growth factor gradient, or chemotaxis, have indicated that PDGF and TGF $\beta$ are chemotactic factors for fibroblasts, neutrophils, and smooth muscle cells. ${ }^{4,12,15,16}$ Such studies have also been undertaken with osteogenic cells. It has been established that PDGF also stimulates the proliferation of human osteoblasts derived from cancellous bone as well as from osteogenic cell lines. ${ }^{17,18}$ In a recent report, Gruber et $\mathrm{al}^{6}$ have demonstrated that not only platelets but PR, platelet microparticles, and platelet membranes are all capable of stimulating the mitogenic activity of human bone-derived cells. Using twodimensional migration assays, PDGF and TGF $\beta$ have been shown to be chemotactic factors for osteogenic cells. ${ }^{19-22}$ Although many increasingly complex migration assays have been developed in the past decade to study stable gradients or three-dimensional migration, ${ }^{23,24}$ osteogenic cells have not been used in such assays.

In this study, it was our aim to develop an in vitro model for the investigation of the effects of PR on bone marrow cell migration, recruitment, and proliferation. Our model, which was extended from the soft tissue healing field, ${ }^{25}$ consisted of a layer of cultured bone marrow cells overlaid with a $1.5-\mathrm{mm}$ fibrin matrix over which PR was added. Using this model, we were able to observe and quantify cell departure from the culture dish and infiltration into the fibrin matrix. Thus, there were two novel aspects of our assay. First, our model allowed for the investigation of three-dimensional migration of osteogenic cells within a biologically relevant fibrin matrix. Second, we used PR containing all factors released by platelets, which was prepared by the activation of platelet concentrate obtained from a commercially available platelet concentrate system. Thus, not only is the in vivo wound healing scenario simulated more closely but, given the clinical use of PR, our study is directly relevant to current healing therapies.

\section{Materials ANd Methods}

\section{Materials}

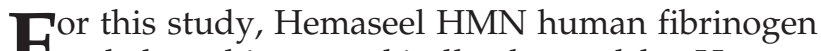
$\boldsymbol{F}$ and thrombin were kindly donated by Haemacure Corporation (Haemacure Corporation, Kirkland, Quebec, Canada). Platelet concentrate was obtained using the Platelet Concentrate Collection System generously provided by Implant Innovations (3i, Palm Beach Gardens, FL). Bone marrow cells were harvested from the femurs of young Wistar rats (115-130 g) (Charles River, St. Constant, Quebec, Canada) and cultured in fully supplemented media (FSM) consisting of $\alpha$-minimal essential media (Faculty of Medicine, University of Toronto, Toronto, Ontario, Canada) supplemented with 15\% (vol/vol) fetal calf serum (GIBCO BRL Life Technologies, Gaithersburg, MD); $50 \mu \mathrm{g} / \mathrm{ml} \mathrm{L}$-ascorbic acid; $5 \mathrm{mM}$ $\beta$-glycerophosphate; $10^{-8} \mathrm{M}$ dexamethasone (Sigma, St. Louis, MO); and a 10\% (vol/vol) antibiotic/Fungizone solution consisting of penicillin G (1670 $\mathrm{U} / \mathrm{ml})$, gentamicin $(500 \mu \mathrm{g} / \mathrm{ml})$, and amphotericin B (3 $\mu \mathrm{g} / \mathrm{ml})$ (Sigma).

\section{Cell Isolation and Culture}

Rat bone marrow cells were obtained according to previously published methods. ${ }^{26,27}$ Briefly, femora were excised from young Wistar rats and transferred into $10 \mathrm{ml}$ of the same antibiotic solution as used in the culture media. Epiphyses were removed, and the marrow from each diaphysis was flushed out with 5 $\mathrm{ml} \mathrm{FSM}$. Marrow cells of both diaphyses were thus collected in a total of $10 \mathrm{ml}$ of FSM to which was added an additional $20 \mathrm{ml}$ of FSM. Fifteen milliliters of this cell suspension was cultured in Falcon T75 flasks (Becton Dickinson Labware, Franklin Lakes, $\mathrm{NJ})$. Cultures were maintained at $37^{\circ} \mathrm{C}$ in an incubator with an atmosphere consisting of $95 \%$ air, $5 \%$ $\mathrm{CO}_{2}$, and $100 \%$ relative humidity. The culture medium was changed every second to third day.

On day 5 or 6 after isolation, depending on when cells reached $\sim 80 \%$ confluency, the cells were subcultured by enzymatic release using $0.01 \%$ trypsin (GIBCO BRL Life Technologies) for 12 to 15 minutes. Cells were counted using a hemacytometer and seeded at a density of 10,000 cells $/ \mathrm{cm}^{2}$ in sixwell plates (Becton Dickinson Labware). This count- 
ing procedure was also used in the proliferation studies.

\section{Fibrin Gel Overlay}

When cells reached confluency after the first subculture, usually after 5 to 6 days, the culture medium was removed and each dish was washed in phosphate-buffered saline (PBS) ( $\mathrm{pH}$ 7.4) (Sigma). Some cultures were treated with the drug cytochalasin-D (Sigma) by incubation for 2 hours at $37^{\circ} \mathrm{C}$ in 50 $\mathrm{mg} / \mathrm{ml}$ cytochalasin-D in FSM. These cultures were washed again twice with PBS before the fibrin gel overlay. Reconstituted fibrinogen $(60 \mathrm{mg} / \mathrm{ml}$ fibrinogen containing $35 \mathrm{IU} / \mathrm{ml}$ factor XIII) and thrombin (500 NIH U/ml) were diluted 1:10 and 1:200, respectively, in FSM containing $225 \mathrm{KIU} / \mathrm{ml}$ aprotinin protease inhibitor from bovine lung (Sigma). A fibrin gel was cast in each culture dish by the addition of equal amounts of diluted fibrinogen and thrombin, which were mixed by gentle hand swirling for 30 seconds to achieve even clot distribution. The final concentrations obtained were $3 \mathrm{mg} / \mathrm{ml}$ fibrinogen and 1.25 $\mathrm{NIH} \mathrm{U/ml} \mathrm{thrombin.} \mathrm{The} \mathrm{gel} \mathrm{was} \mathrm{allowed} \mathrm{to} \mathrm{poly-}$ merize for 30 minutes in the incubator, resulting in a fibrin clot overlying the cells. For subsequent culture, $2 \mathrm{ml} \mathrm{FSM}$ with $225 \mathrm{KIU} / \mathrm{ml}$ aprotinin protease inhibitor was added on top of the gels; this medium was used for all experimental groups and in all subsequent media changes (Fig 1).

\section{Platelet Releasate}

Some experimental groups contained PR added to the media on top of the fibrin gel. To obtain PR, platelet concentrate was initially obtained using the $3 i$ Platelet Concentrate Collection System. Briefly, 54 $\mathrm{ml}$ whole blood was obtained from a healthy, consenting volunteer (two donors with 1-2 donations each were used for this study) and mixed with $6 \mathrm{ml}$ sodium citrate anticoagulant (Cytosol Laboratories, Braintree, MA). The blood was transferred to the collection system and subjected to two centrifugation cycles. Red blood cells were removed after the first centrifugation, and a platelet pellet was obtained after the second, which was resuspended in 6 to $8 \mathrm{ml}$ overlying plasma. We have demonstrated an average sevenfold increase in platelet count relative to whole blood using the Platelet Concentrate Collection System (not shown), which is consistent with published results. ${ }^{11}$ For subsequent use, platelet concentrate was stored at room temperature with gentle agitation for up to 3 days.

Platelets were allowed to rest for 30 minutes and were then activated by incubation with 2 IU human thrombin per milliliter (Hemaseel HMN; Haemacure Corporation) for 15 minutes at room temperature. An equal amount of FSM was added, and the mixture was centrifuged at $2000 \mathrm{~g}$ for 10 minutes. The supernatant containing the released platelet factors was removed and filtered with a $0.22-\mu \mathrm{m}$ filter (Millipore, Bedford, MA). Platelet supernatant was added in dilutions of 1:4 (vol/vol) in FSM with aprotinin to different experimental groups at various time points (Table 1). Some groups received human recombinant PDGF-BB (Sigma) added to the media on top of the gel at a concentration of $20 \mathrm{ng} / \mathrm{ml} \mathrm{FSM}$. Medium changes were performed every other day.

Five days after the fibrin gel overlay, cell cultures were fixed in a solution of $2 \%$ glutaraldehyde and $2 \%$ formaldehyde in PBS at $4{ }^{\circ} \mathrm{C}$ for a minimum of 1.5 hours. Samples were washed three times in PBS after fixation and prepared for confocal microscopy or transmission electron microscopy (TEM).

\section{Confocal Laser Light Microscopy}

For confocal microscopy, fixed cultures were first permeablized with $0.1 \%$ Triton X-100 in PBS for 90 seconds (Sigma) and labeled with a solution of 5 $\mu \mathrm{l} / \mathrm{ml}$ fluorescein isothiocyanate phalloidin (Alexa Fluor 488; Molecular Probes, Eugene, OR), an F-actin stain, and $0.7 \mu \mathrm{l} / \mathrm{ml}$ ethidium homodimer (Molecular Probes), a nuclear stain, in PBS for 20 minutes. The microscopy was performed using the Zeiss LSM 510 confocal microscope (Zeiss, Thornwood, NY) equipped with $a \times 40$ Axiovert water lens. Sectional images were taken along the $\mathrm{Z}$ axis. Cross-sectional images were computed from the Z stack data by LSM 3.80 software (Zeiss). To quantify cell migration, cultures were analyzed at 15 random fields on the culture dish for three dishes per experimental group. The thickness of fibrin gels was measured using the stage height function on the LSM 510 microscope.

Table 1. Experimental Groups, Abbreviations and Respective Culturing Conditions

\begin{tabular}{lcc}
\hline & \multicolumn{2}{c}{ Culturing Media on Days after Subculture } \\
\cline { 2 - 3 } $\begin{array}{l}\text { Experimental } \\
\text { Group }\end{array}$ & Day 5 & Day 7 \\
\hline Negative control & FSM & FSM \\
PR - 5 & FSM supplemented & FSM \\
& with PR & \\
PR - 5, 7 & FSM supplemented & FSM supplemented \\
& with PR & with PR \\
PR - 5 & FSM & FSM supplemented \\
& & with PR \\
\hline
\end{tabular}

FSM, fully supplemented media; PR, platelet releasate. 


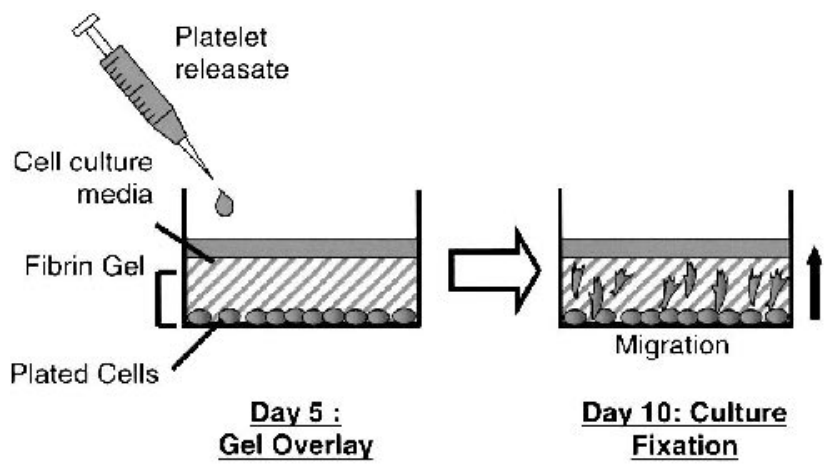

Fig 1 Experimental method. Rat bone marrow cells were subcultured in 35-mm tissue culture dishes. After cells reached $\sim 80 \%$ confluency, usually on day 5 of subculture, a fibrin gel was overlaid. Medium was added on top of the gel, and platelet releasate was added to the medium in some culture groups. The culture medium was refreshed on day 7 , and cultures were fixed on day 10, allowing cell migration to proceed for a total of 5 days.

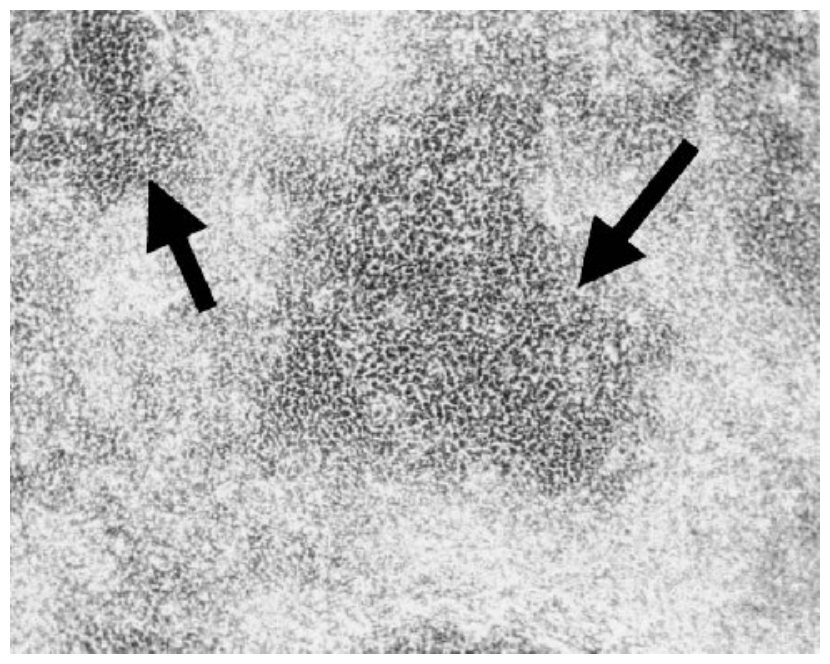

Fig 2 Bone nodule formation, as indicated by the arrows, observed by light microscopy in cultures at time of fixation. The field width is $1,125 \mu \mathrm{m}$.
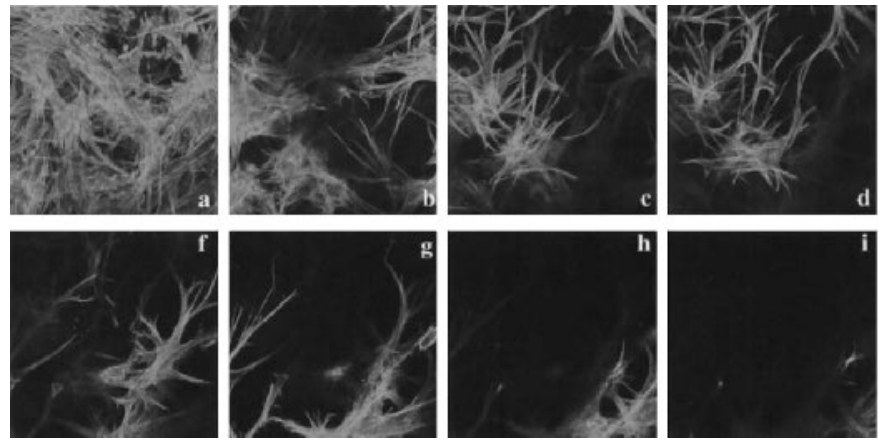

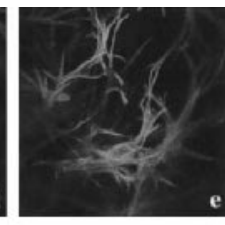

Measured fibrin gel heights in groups with cells were compared with fibrin gels without cells that were cast on the same day and maintained under the same conditions.

\section{Transmission Electron Microscopy Analysis}

For TEM analysis, samples were fixed using Karnovsky solution (2\% paraformaldehyde and 2.5\% glutaraldehyde in $0.1 \mathrm{M} \mathrm{Na}$-cacodylate at $\mathrm{pH} 7.3$ ) at $4^{\circ} \mathrm{C}$ for 4 hours. After fixation, cell cultures were postfixed in $2 \%$ osmium tetroxide in $0.1 \mathrm{M} \mathrm{Na}$ cacodylate for 90 minutes at room temperature to preserve the cell membranes. Subsequently, samples were dehydrated in graded ethanol and thoroughly washed before en bloc staining with uranyl acetate in $50 \%$ ethanol for 2 hours at room temperature. Specimens were again dehydrated in graded alcohols and subsequently infiltrated with a series of alcohol-Epon mixtures before two final changes with pure Epon. After Epon polymerization at $40^{\circ} \mathrm{C}$ overnight and afterward at $60^{\circ} \mathrm{C}$ for 3 days, selected areas of the tissue were re-embedded in beam capsules. Silver to pale gold, thin, transverse sections were cut on an ultra microtome and mounted on copper grids. Sections were stained with 3\% uranyl acetate in 30\% ethanol and afterward with Reynold lead citrate. Samples were examined with a Phillips 400T transmission electron microscope and, in the case of electron diffraction, with a Phillips EM 430 transmission electron microscope. Electron diffraction patterns were projected directly onto a photographic plate.

\section{Statistical Analysis}

Experiments were performed in duplicate for $3 \leq \mathrm{n}$ $\leq 5$. For each experiment, the error in all results was expressed as the SD for the indicated number of experimental groups. Statistical significance of the results was determined by the paired, one-tailed, Student $t$ test. $P$ values less than 0.05 were considered significant.

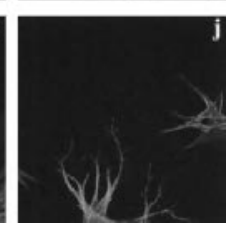
tained by confocal microscopy. The image series $(a-j)$ begins at the bottom of the culture dish (a), where a confluent cell layer is visible, and proceeds up through the unstained fibrin gel. Cells are stained green for F-actin, rendering the cell body and extended cell processes clearly visible. The vertical distance between images is $15 \mu \mathrm{m}$, and the field width is $265 \mu \mathrm{m}$.
Fig 3 Series of horizontal images ob- 


\section{Results}

$\mathbf{H}$ arvested rat bone marrow cells were cultured in vitro as described previously. Bone nodule formation was observed by light microscopy (Fig 2). Bone nodules were first detected on day 4 or 5 after subculture and continued to appear and expand until fixation in both control and fibrin overlaid groups.

Confocal microscopy revealed extensive penetration of the cells into the unlabeled fibrin matrix (Fig 3) after 5 days. The cells observed within the fibrin matrix had the characteristic elongated morphology of migrating cells ${ }^{28}$ with many cell processes projecting into the fibrin gel.

To confirm the viability of the model, it was important to determine if on fibrin gel overlay, cells became trapped within the fibrin gel. To investigate this possibility, some experimental groups were fixed an hour after gel overlay. Analysis by confocal microscopy showed that no cells were present within the fibrin matrix in these groups.

The leading front of migration, or the furthest vertical distance migrated by any one cell into the fibrin gel, as well as the total number of migrating cells in the volume above the analyzed points was determined. Statistically significant differences in terms of these two parameters were observed between groups treated with growth factors in the form of PR and those without. In the experimental groups that received PR at the early stage of culture (PR 5 and PR 5,7) the average leading front was $20 \%$ to $25 \%$ greater than in control groups (Fig 4). In these groups, the average leading front ranged from 255 to $275 \mu \mathrm{m}$ (equivalent to $50-55 \mu \mathrm{m} / \mathrm{d}$ ), which corresponds well with published in vivo data. ${ }^{29}$ An even more striking difference between groups was observed by counting the total number of migrating cells. Close to a 3-fold increase in the number of migrating cells was observed in PR 5 and PR 5,7 groups as compared with controls (Fig 5).

In groups treated with PDGF instead of PR at parallel time points, a 1.5-fold increase in the number of migrating cells was measured in PDGF 5 and PDGF 5,7 groups as compared with untreated controls (data not shown).

Transmission electron microscopy analysis was performed to examine the presence or absence of signs of de novo bone formation within the fibrin gel, thus confirming that a percentage of the migrating cells were indeed osteogenic. Given that the cellular infiltrate was characterized by stellate-shaped cells, the TEM cross section often only showed cell processes rather than cell bodies (Fig 6A). In proximity to the cellular infiltrate, spherical electron-dense

\section{Average Leading Front of Migration}

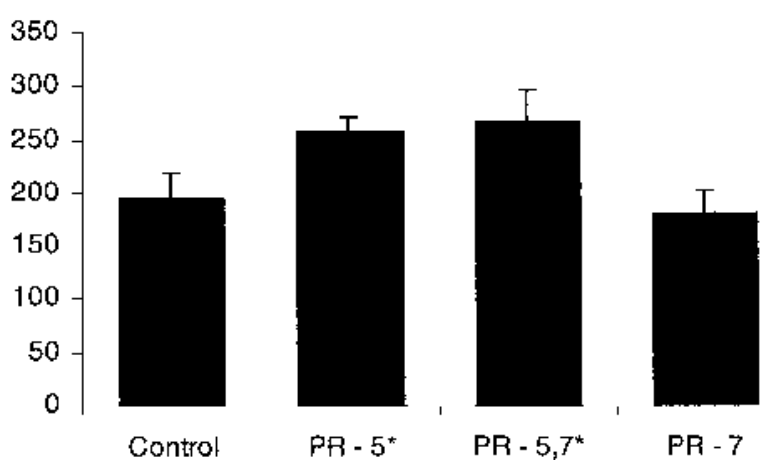

Fig 4 Average leading front of migration (furthest distance traveled by any one cell at analyzed point) in micrometers as determined by confocal microscope analysis at 15 points per well for three wells. ${ }^{*}$ Statistically significant results compared with control $(P<0.05)$.

bodies approximately 0.5 to $1 \mu \mathrm{m}$ in diameter could be observed within the fibrin matrix. At higher magnification, the electron-dense bodies within the fibrin matrices appeared to contain needle-shaped crystallites (see Fig 6B). The presence of mineral within the electron-dense bodies was supported by TEM electron diffraction analysis. Diffraction patterns obtained from areas with electron-dense bodies revealed circular banding patterns (see Fig 6C) characteristic for hydroxyapatite. ${ }^{30}$

To examine further the mechanisms of action of

\section{Total Number of Migrating Cells}

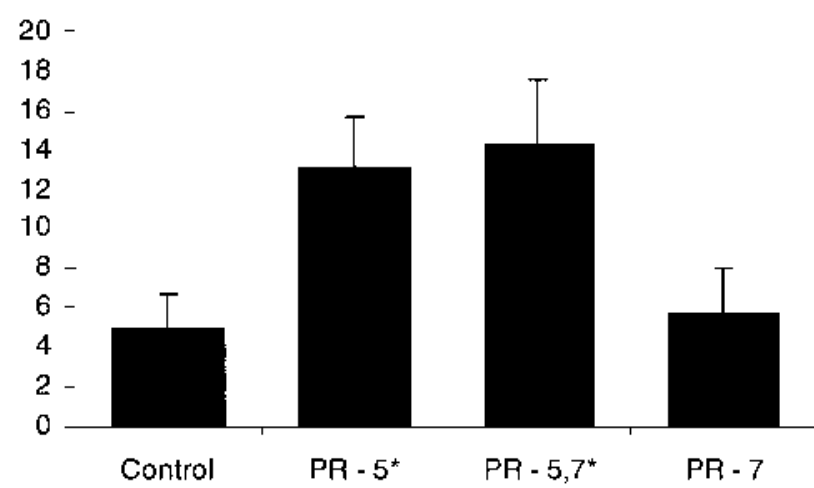

Fig 5 Total number of migrating cells as counted in the volume above the confluent cell layer at specific analyzed points given as average of 15 points per well for three wells. *Statistically significant results compared with control $(P<0.05)$. 

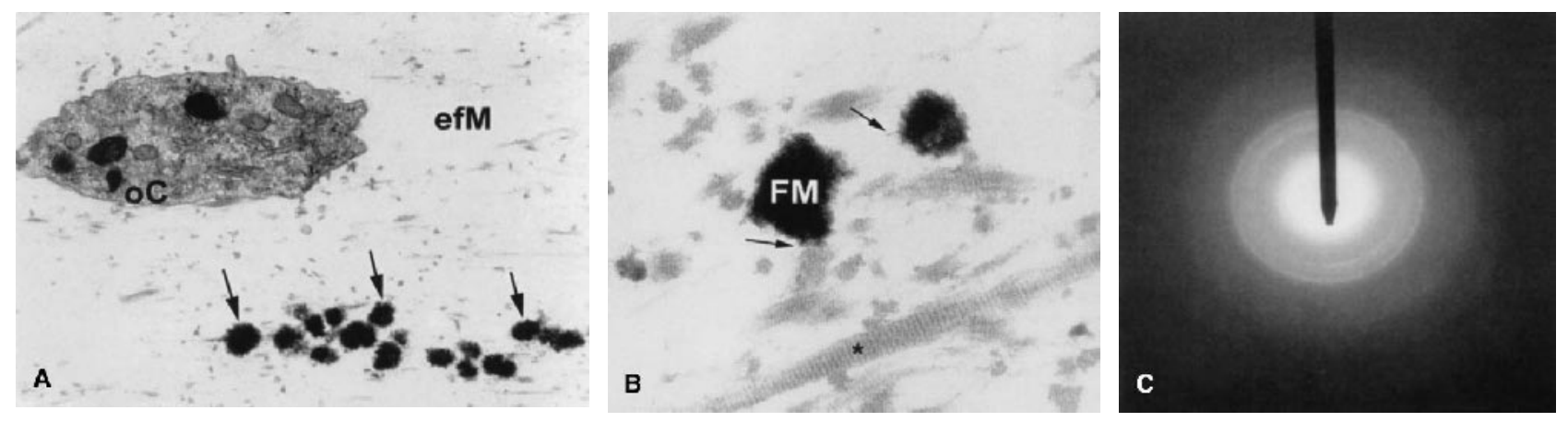

Fig 6 Transmission electron microscopy photomicrographs (A and B) and electron diffraction pattern (C) indicating the presence of de novo bone formation within fibrin gels infiltrated by rat bone marrow cells. (A) An anuclear branch of an osteogenic cell $(\mathrm{oC})$ containing several catabolic organellae can be seen embedded within the extracellular fibrinous matrix (efM). In proximity to the cell branch, several spherical electron-dense bodies on the order of $0.5 \mu \mathrm{m}$ (arrows) are visible. The field width is $10 \mu \mathrm{m}$. (B) At higher magnification, individual needle-shaped particles (arrows) are visible within the electron-dense spherical bodies. The field width is $1.7 \mu \mathrm{m}$. (C) The presence of hydroxyapatite in the electron-dense bodies is confirmed by the circular electron diffraction pattern. ${ }^{30}$

PR during wound healing, the effect of PR on cell proliferation was also studied. The proliferation studies were conducted in the absence of fibrin but using the same culture conditions as described previously. Platelet releasate had a significant effect on cell proliferation, causing a 1.5 to 2 -fold increase in cell numbers as observed at the time of fixation (Fig 7). Platelet-derived growth factor alone caused a maximum 1.5-fold increase in cell numbers in the PDGF 5,7 group. Gruber et $\mathrm{al}^{6}$ have recently shown that PR is able to elicit a mitogenic response in human trabecular bone-derived cells but did not generate a growth curve or confirm the osteogenic potential of the harvested cells.

To investigate whether the presence and migration of cells within the three-dimensional fibrin matrix had any effect on the gel, contraction of the fibrin gel was characterized after the culture period. No statistically significant vertical or horizontal contraction of the gel was observed in the absence of cells (not shown). Furthermore, all gels remained firmly attached to the sides of the culture wells, indicating the absence of horizontal contraction. Microscopically aided measurement of the thickness of the fibrin gel revealed significant vertical contraction after the 5-day culture period, however. To investigate further the cause of such contraction, cells were treated with cytochalasin-D, which blocks actindependent cell processes such as cell migration by capping actin filaments. ${ }^{31}$ As shown in Figure 8, these cells exhibited only minimal migration as compared with untreated cells. Examination of the vertical thickness of these gels showed that significant contraction of the fibrin matrix occurred in the presence of untreated cells after the 5-day culture period. This contraction was further enhanced in the presence of PR. When migration was inhibited by cytochalasin-D, however, gel contraction was also strikingly reduced (Fig 9).

\section{Cell Proliferation}

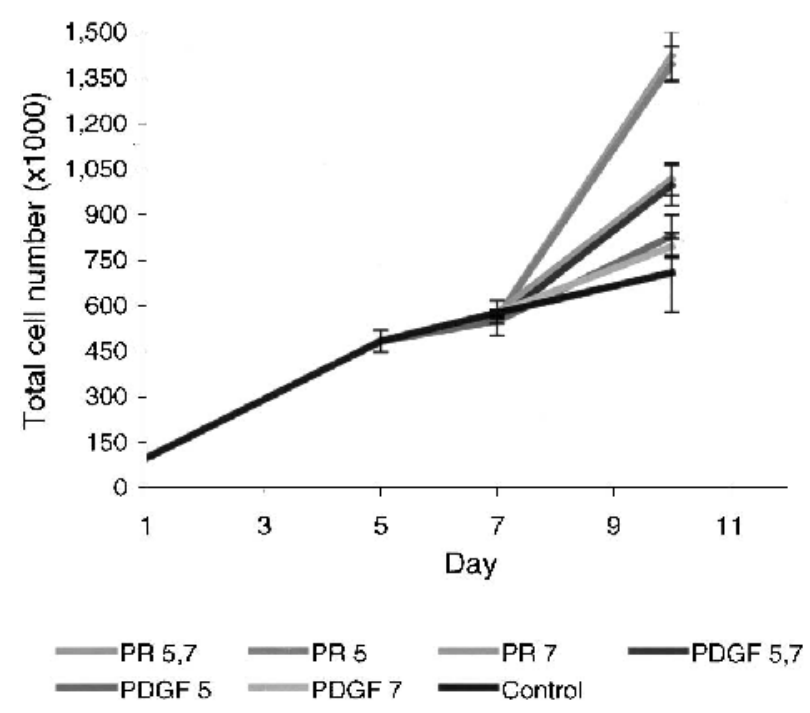

Fig 7 Cell proliferation in the absence of fibrin under standard culture conditions (control) or with added growth factors at days after subculture. Groups listed in order of appearance from top to bottom. Values given as average of three samples counted per group. 


\section{Leading Front of Migration}

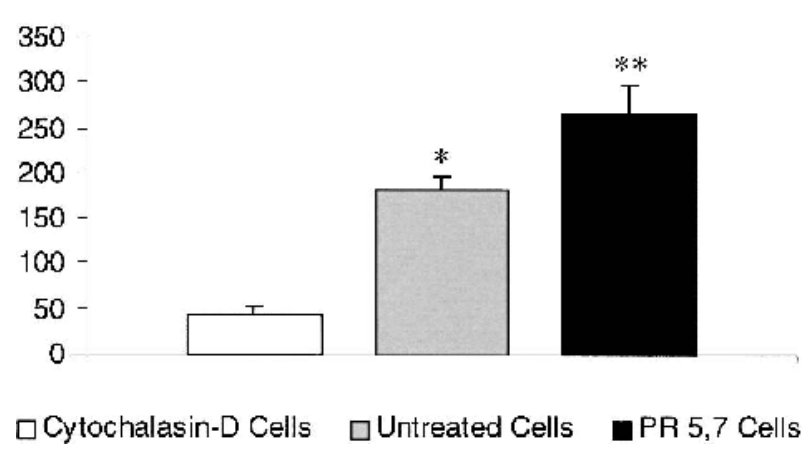

Fig 8 Leading front of migration as recorded from confocal microscopy given as an average of 15 points for three wells per experimental group. *Statistically significant groups as compared with cytochalasin-D-treated cells. **Statistically significant group as compared with cytochalasin-D and untreated cells.

\section{DISCUSSION}

I n the current study, we present a new in vitro assay to elucidate the effects of PR on osteogenic cell recruitment, migration, and proliferation. Our model consisted of a layer of rat bone marrow cells cultured under osteogenic conditions overlaid by a fibrin gel in the presence or absence of PR. Using this model, we were able to observe and quantify the effects of PR on osteogenic cell migration and recruitment in a biologically relevant fibrin matrix.

Using confocal microscopy, it was observed that rat bone marrow cells were capable of extensive in-

\section{$\%$ Vertical Fibrin Gel Contraction}

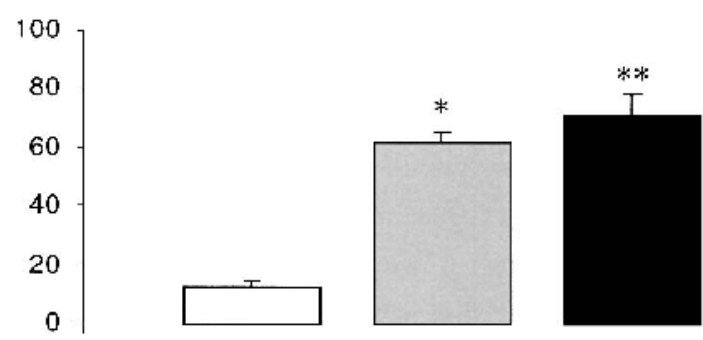

$\square$ Cytochalasin-D Cells aUntreated Cells aPR 5,7 Cells

Fig 9 Gel contraction expressed as percentage of contraction of vertical fibrin gel height at the time of fixation as compared with height of gel at the time of casting. *Statistically significant groups as compared with cytochalasinD-treated cells. ${ }^{*}$ Statistically significant group as compared with cytochalasin-D and untreated cells. filtration of fibrin matrices in vitro (see Fig 3). Furthermore, TEM analysis indicated the presence of globular foci of mineralization in the proximity of the cells infiltrating the fibrin gels (see Fig 6A), which were morphologically similar to globules we have observed both in vitro during de novo bone formation at solid surfaces and in vivo in advance of the bone front in the closing sagittal suture of rats. ${ }^{1,32}$ The presence of such mineralization foci throughout the fibrin gel indicates that among the multiple bone marrow cell populations, osteogenic cells were indeed infiltrating the fibrin matrices. It can further be concluded that the observed cell migration was an active cellular process because it proceeded counter to gravity and it was confirmed that cells were not trapped within the fibrin gel during the overlay procedure. This was also supported by the observed cell morphology, with the elongated cell body and extended cell processes that are characteristic features of cell migration in three dimensions. ${ }^{28}$

To determine the effects of PR on cell migration and recruitment, two parameters were investigated, namely, the leading front of migration and the number of migrating cells. The addition of PR caused a significant increase in the leading front of migration when added early during culturing (Groups PR 5 and PR 5,7), but no effect was observed when it was added later as in the PR 7 group. Thus, PR has a stimulatory effect on cell migration but seems to be associated with a lag period. It is also reasonable to assume that a gradient was initially present across the fibrin gel and that cells migrated vertically upward through the gel in response to this gradient. No conclusive distinction between chemotaxis and chemokinesis can be made based on these data, however, and additional work is necessary to confirm the extent to which the gradient was maintained over the duration of the experiment.

The most striking effect of PR was on the number of migrating cells within the fibrin matrix. The early addition of PR in the PR 5 and PR 5,7 groups caused a 3- to 3.5-fold increase in the number of migrating cells (see Fig 5). To distinguish whether this increase was caused by the recruitment of a greater number of cells to migrate or by enhanced proliferation of the same initial number of migrating cells in the presence of the PR, we can compare the migration data with data obtained in the proliferation studies (see Fig 7). If we suppose that the number of migrating cells doubled as a result of proliferation as indicated by the proliferation studies, a greater number of cells still had to be initially stimulated to migrate to account for the greater than 3-fold increase in the number of migrating cells in the PR 5 and PR 
5,7 groups. A further examination of the PR 7 group shows that although PR stimulated a 1.5-fold increase in cell proliferation, an increase in the number of migrating cells was not observed in this group as compared with controls. Thus, it appears that increased recruitment stimulated by PR is the more significant factor contributing to an increase in the number of migrating cells within the fibrin gel. The addition of PR therefore stimulates an increase in the migration of osteogenic cells through three mechanisms: first, by recruiting more cells to detach from the culture dish or neighboring cells and to begin to migrate within the fibrin gel; second, by stimulating an increase their migratory activity; and, third, by stimulating cell proliferation.

One parameter that must be taken into consideration, however, is that the proliferation data were obtained from adherent cells on a two-dimensional surface. Proliferation can be significantly affected by the extracellular environment. ${ }^{33}$ Thus, the rate of division of cells on a two-dimensional surface can be significantly different than in a three-dimensional biological matrix. Studies that have addressed this issue have not offered consistent trends, however. ${ }^{33}$ Fibroblast studies suggest that proliferation in three dimensions compared with two dimensions is either unchanged, ${ }^{34}$ inhibited, ${ }^{35}$ or stimulated. ${ }^{36}$ Such data are currently not available for bone marrow-derived cells. Our data from the PR 7 group seems to indicate that cell proliferation is in fact reduced within the fibrin gels, given that the 1.5-fold increase in cell number that was seen when cells were cultured in two dimensions did not translate to cells within the three-dimensional fibrin gel.

Using this assay, we were further able to investigate the effects of cell migration on fibrin gel contraction. Measurement of fibrin gel height at the time of fixation indicated a substantial vertical contraction of the gels in the presence of cells compared with acellular controls. When cells were treated with cytochalasin-D, a chemical used to block active cell migration, ${ }^{31}$ migration was strongly inhibited (see Fig 8), as was gel contraction (see Fig 9). CytochalasinD-treated groups exhibited only $20 \%$ of the contraction observed in untreated groups. These results indicate that matrix contraction is directly related to the migratory activity of cells, because inhibition of cell migratory activity resulted in reduced gel contraction. The contractile forces generated during migration are well known ${ }^{37}$ and have been previously postulated to be responsible for matrix contraction in soft tissue wound healing. ${ }^{33}$

Furthermore, gel contraction was enhanced by the presence of added growth factors. Experimental groups that contained added PR showed statistically more gel contraction than cell controls without added factors (see Fig 9). This supports our previous observation that a greater number of cells were found migrating further in these groups. It follows that an increase in gel contraction is expected.

In this study, a novel in vitro model for the study of the recruitment and migration of osteogenic cells was developed. Using this model, it was determined that PR stimulates the recruitment, migration, and proliferation of bone marrow-derived cells. The model also allowed us to determine that fibrin matrix contraction is directly related to cell migration.

The authors thank the Haemacure Corporation for the providing the fibrin used in this study.

Financial support was provided by Implant Innovations and an Ontario Research and Development Challenge Fund, Canada grant to J.E. Davies.

\section{REFERENCES}

1. Davies JE, Hosseini MM. Histodynamics of endosseous wound healing. In: Davies JE (ed). Bone Engineering. Toronto: em squared Inc, 2000:1-4

2. Park JY, Gemmell CH, Davies JE. Platelet interactions with titanium: modulation of platelet activity by surface topography. Biomaterials 2001;22:2671-2682

3. Marx RE. Platelet concentrate: a strategy for accelerating and improving bone regeneration. In: Davies JE (ed). Bone Engineering. Toronto: em squared Inc, 2000:447-453

4. Deuel TF, Senior RM, Huang JS, et al. Chemotaxis of monocytes and neutrophils to platelet-derived growth factor. J Clin Invest 1982;69:1046-1049

5. Mustoe TA, Pierce GF, Morishima C, et al. Growth factorinduced acceleration of tissue repair through direct and inductive activities in a rabbit dermal ulcer model. J Clin Invest 1991;87:694-703

6. Gruber R, Varga F, Fischer MB, et al. Platelets stimulate proliferation of bone cells: involvement of platelet-derived growth factor, microparticles and membranes. Clin Oral Implants Res 2002;13:529-535

7. McClain SA, Simon M, Jones E, et al. Mesenchymal cell activation is the rate limiting step of granulation tissue induction. Am J Pathol 1996;149:1257-1269

8. Howes R, Bowness JM, Grotendorst GR, et al. Platelet-derived growth factor enhances demineralized bone matrix-induced cartilage and bone formation. Calcif Tissue Int 1988;42:34-38

9. Lowery GL, Kulkarni S, Pennisi AE. Use of autologous growth factors in lumbar spinal fusion. Bone 1999;25(Suppl):47S-50S

10. Marx RE, Carlson ER, Eichstaedt RM, et al. Platelet-rich plasma: growth factor enhancement for bone grafts. Oral Surg Oral Med Oral Pathol Oral Radiol Endod 1998;85:683-746

11. Weibrich G, Kleis WKG. Curasan PRP kit versus PCCS PRP system. Clin Oral Impl Res 2002;13:437-443

12. Seppa H, Grotendorst G, Seppa S, et al. Platelet-derived growth factor is chemotactic for fibroblasts. J Cell Biol 1982;92: 584-588

13. Betsholtz C, Westermark B. Growth factor-induced proliferation of human fibroblasts in serum-free culture depends on cell density and extracellular calcium concentration. J Cell Physiol 1984;118:203-210 
THE JOURNAL OF CRANIOFACIAL SURGERY / VOLUME 14, NUMBER 3 May 2003

14. Ishikawa O, LeRoy EC, Trojanowska M. Mitogenic effect of transforming growth factor beta 1 on human fibroblasts involves the induction of platelet-derived growth factor alpha receptors. J Cell Physiol 1990;145:181-186

15. Postlethwaite AE, Keski-Oja J, Moses HL, et al. Stimulation of the chemotactic migration of human fibroblasts by transforming growth factor beta. J Exp Med 1987;165:251-256

16. Lucas PA, Caplan AI. Chemotactic response of embryonic limb bud mesenchymal cells and muscle-derived fibroblasts to transforming growth factor-beta. Connect Tissue Res 1988;18: $1-7$

17. Graves DT, Valentin-Opran A, Delgado R, et al. The potential role of platelet-derived growth factor as an autocrine or paracrine factor for human bone cells. Connect Tissue Res 1989;23: 209-218

18. Tsukamoto T, Matsui T, Fukase M, et al. Platelet-derived growth factor B chain homodimer enhances chemotaxis and DNA synthesis in normal osteoblast-like cells (MC3T3-E1). Biochem Biophys Res Commun 1991;175:745-751

19. Pfeilschifter J, Wolf O, Naumann A, et al. Chemotactic response of osteoblast like cells to transforming growth factor beta. J Bone Miner Res 1990;5:825-830

20. Hughes FJ, Aubin JE, Heersche JN. Differential chemotactic responses of different populations of fetal rat calvaria cells to platelet-derived growth factor and transforming growth factor beta. J Bone Miner Res 1992;19:63-74

21. Chandrasekhar S, Harvey AK. Modulation of PDGF mediated osteoblast chemotaxis by leukemia inhibitory factor. J Cell Physiol 1996;169:481-490

22. Lind M. Growth factor stimulation of bone healing: effects on osteoblasts, osteotomies, and implant fixation. Acta Orthop Scand Suppl 1998;283:2-37

23. Knapp DM, Helou EF, Tranquillo RT. A fibrin or collagen gel assay for tissue cell chemotaxis: assessment of fibroblast chemotaxis to GRGDSP. Exp Cell Res 1999;247:543-553

24. Leon NL, Baskaran H, Dertinger SKW, et al. Neutrophil chemotaxis in linear and complex gradients of interleukin-8 formed in a microfabricated device. Nat Biotechnol 2002;20: $826-830$

25. Brown LF, Lanir N, McDonagh J, et al. Fibroblast migration in fibrin gel matrices. Am J Pathol 1993;142:273-283

26. Davies JE, Chernecky R, Lowenberg B, et al. Deposition and resorption of calcified matrix in vitro by rat bone marrow cells. Cells Mater 1991;1:3-15

27. Davies JE. In vitro modeling of the bone/implant interface. Anat Rec 1996;245:426-445

28. Lauffenburger DA, Horwitz AF. Cell migration: a physically integrated molecular process. Cell 1996;84:359-369

29. Winet H, Bao JY, Moffat R. Neo-osteogenesis of haversian trabeculae through a bone chamber implanted in a rabbit tibial cortex: a control model. Calcif Tissue Int 1990;47:24-34

30. Tenenbaum HC, Palangio KG, Holmyard DP, et al. An ultrastructural study of osteogenesis in chick periosteum in vitro. Bone 1986;7:295-302

31. Pederson SF, Hoffmann EK, Mills JW. The cytoskeleton and cell volume regulation. Comp Biochem Physiol A Mol Integr Physiol 2001;130:385-399

32. Hosseini MM. On the Relationship Between Osteoconduction and Surface Texture During Peri-Implant Osteogenesis [PhD thesis]. Toronto: Institute for Biomaterials and Biomedical Engineering, University of Toronto, 2001

33. Friedl P, Brocker EB. The biology of cell locomotion within three-dimensional extracellular matrix. Cell Mol Life Sci 2000; 57:41-64

34. Tuan $\mathrm{T}$, Song $\mathrm{A}$, Chang $\mathrm{S}$, et al. In vitro fibroplasias: matrix contraction, cell growth and collagen production of fibroblasts cultured in fibrin gels. Exp Cell Res 1996;223:127-134

35. Mio T, Adachi Y, Romberger DJ, et al. Regulation of fibroblast proliferation in 3-dimensional collagen gel matrix. In Vitro Cell Dev Biol Anim 1996;32:427-433

36. Cukierman E, Pankov R, Stevens DR, et al. Taking cell matrix adhesions to the $3^{\text {rd }}$ dimension. Science 2001;294:1708-1712

37. Harris AK, Wild P, Stopak D. Silicone rubber substrata: a new wrinkle in the study of cell locomotion. Science 1980;208:177179 